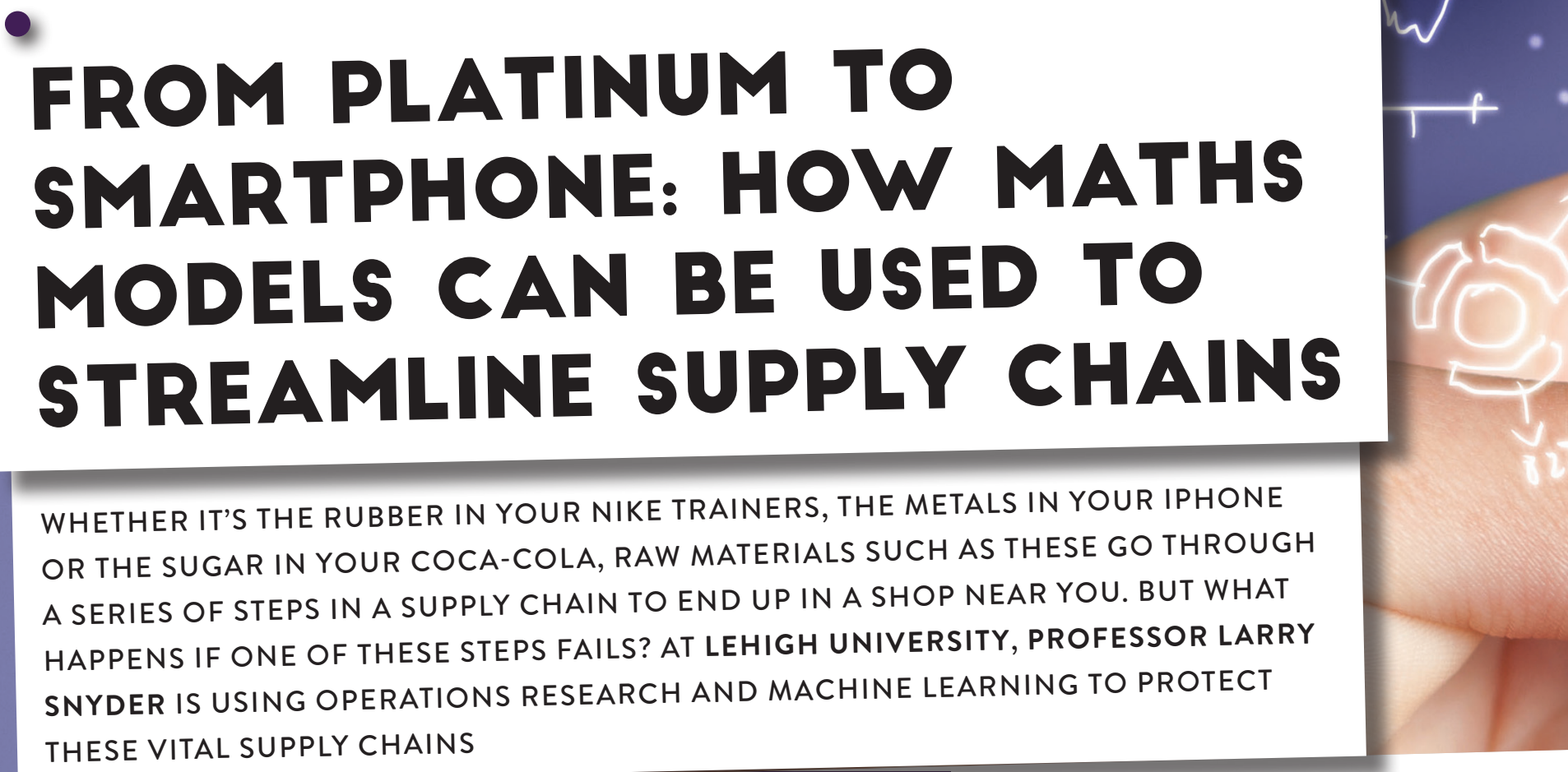

TO MAKE SLIP-ON SHOES, VAN'S HAS TO SOURCE MATERIALS FROM OVER 75 DIFFERENT SUPPLIERS WORLDWIDE!

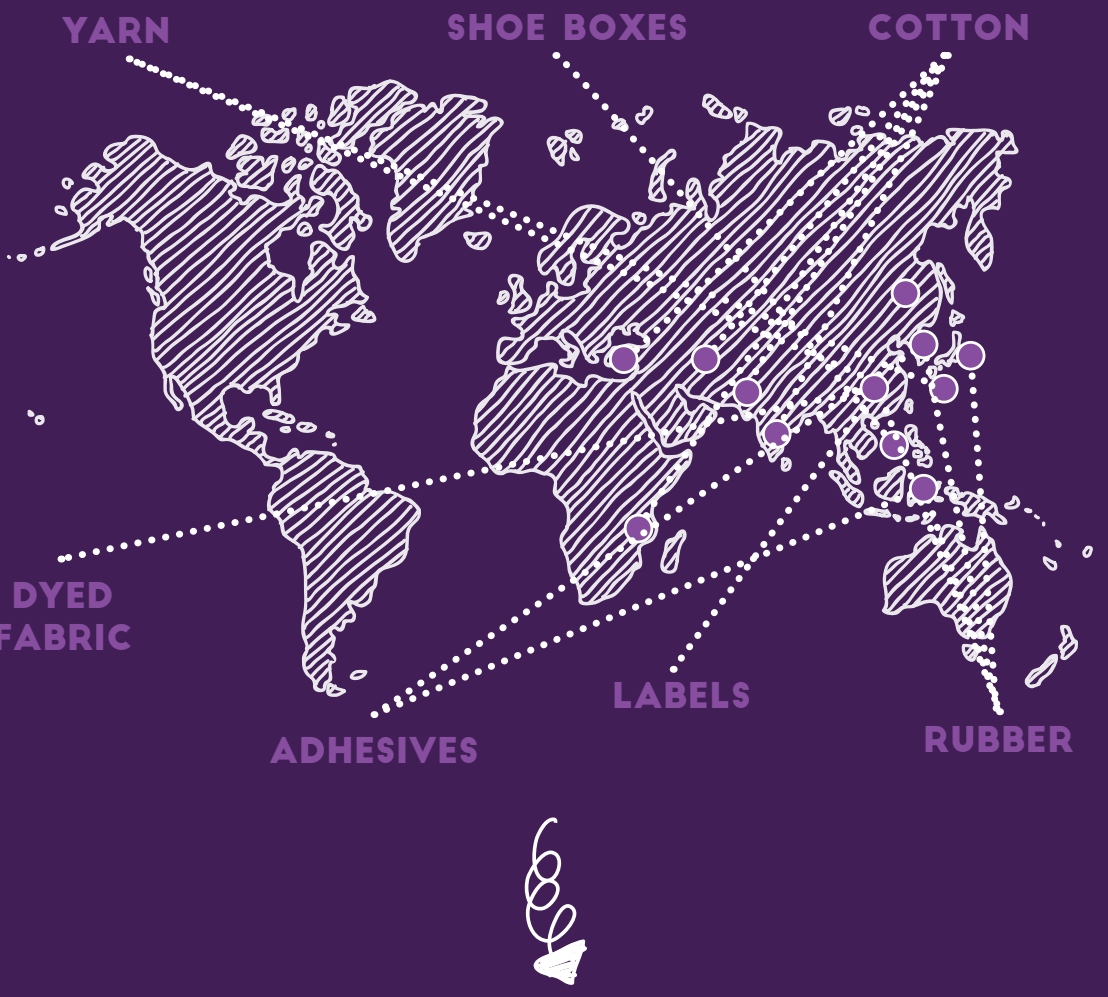

ANYTHING COULD GO WRONG AT ANY POINT. WITHOUT PROPER MANAGEMENT, PROBLEMS IN THE SUPPLY CHAIN CAN CAUSE HOLDUPS IN SHOE PRODUCTION, DISTRIBUTION AND SALES. MANAGING THIS CHAIN IS MASSIVELY IMPROVED WITH COMPUTER MODELLING AND OPERATIONS RESEARCH.
Every organisation, whether a restaurant or hospital, depends to some extent on factors out of their control: workers in another

factory, a cargo ship departing punctually, the weather. The sequence of steps required for a product or service to make it from the development stage to sale is called a supply chain. Larry Snyder, Professor of Industrial and Systems Engineering at Lehigh University, uses operations research to build computer models that can optimise and protect these supply chains.

\section{WHAT IS SUPPLY CHAIN}

MANAGEMENT?

Supply chain management is the management of the flow of goods from the source of the raw materials, through to the production process, all the way to the consumer. A supply chain ends with a customer getting the product or service they want. Think of coffee beans in Costa Rica, for example, and all of the processes that need to happen to turn these coffee beans into coffee that can be sold in coffee shops or supermarkets. There are a lot of hidden steps that consumers never see, from the harvesting of the beans to the processing, packaging and transportation. But what happens if floods damage the crops in Costa Rica, or a fire breaks out in the processing factory? A failure at any stage in the supply chain can cause a chain reaction, delaying later steps, and creating a shortage at the consumer end - this is known as supply chain disruption. Good supply chain management is about creating supply chains that can withstand these disruptions without leading to a shortage of supplies or services. 


\section{ABOUT OPERATIONS RESEARCH AND MACHINE LEARNING}

Operations research is a set of mathematical and computational tools for evaluating, analysing and optimising complex systems. In other words, these tools help systems run as efficiently as possible, and continue to work well during unforeseen problems such as natural disasters, strikes or equipment failure. Operations research is used by companies in nearly every industry, as well as by governments and non-profit organisations. "Whenever an organisation has a problem with huge numbers of possible combinations or lots of randomness, operations research can help," says Larry. He lists the following examples:

\section{- Airlines use operations research to decide} where to fly and when, which aircraft to fly on which flights, and which pilots to assign to each flight.

- Hospitals use operations research to improve the efficiency of patient flows, to manage the inventory of life-saving supplies, and to schedule operating rooms.

- Non-profit organisations use operations research to decide how to get relief supplies to disaster victims quickly, how to allocate resources fairly, and how to plan evacuation routes.

\section{WHAT IS MACHINE LEARNING?}

"Even though the phrase 'machine learning' conjures up images of cyborg butlers and computerised doctors, it's really just a set of computer programs, or algorithms, which help computers perform tasks that are traditionally thought of as part of human intelligence. For example, machine learning algorithms have recently gotten good at identifying images, translating text and even playing computer games!" says Larry.

"Imagine you want to write an algorithm to play chess," Larry continues. "One approach would be to build certain fixed rules or preferences into the algorithm, like 'it's worse to lose your queen than your rook' or 'it's good to double your opponent's pawns.' Machine learning algorithms, though, don't tend to be rule-based. Instead, they're designed to 'learn' which moves are good or bad on their own without being told explicitly. They do this either by analysing a large volume of data, or by simulating a task (like playing chess) many, many times and learning what works and what doesn't."

However, as Larry says, "Machine learning is one of many tools in the operations research toolbox. It's a hugely powerful tool for some jobs, and not the right tool for others."

\section{IF COMPUTERS CAN ANSWER} COMPLEX MATHS PROBLEMS FOR US, WHY SHOULD STUDENTS CONSIDER STUDYING MATHS?

Computers are really good at calculations, but maths is about much more than number crunching. "If you want to write a computer program that will design a bridge, you have to understand structural engineering before you can write the program. If you want to write an autopilot program for an aeroplane, you have to understand aerodynamics," says Larry. "By the same token, if you want to write a program to solve maths problems, you have to understand the maths."
The importance of human input into operations research is highlighted by a famous operations research problem: the travelling salesman problem. "You are given a set of cities, and you have to find the shortest route that visits every city (and returns to the starting point)." Explains Larry, "One naive way of solving this problem is to program a computer to try every possible sequence of cities and pick the shortest one. If there are $n$ cities, then there are $n !$ ( $n$ factorial) sequences. If your travelling salesman needed to visit 50 cities and your computer could check 1 quadrillion sequences per second, it would take your computer over $964,424,568$, 801,000,000,000,000,000,000,000, $000,000,000$ years to solve the problem!"

Human input, in the form of operations researchers, is essential. More complex algorithms need to be designed to solve problems such as this one. "Today's algorithms can solve a 50-city travelling salesman problem in a fraction of a second," says Larry. "Those algorithms use lots of maths, especially fields like combinatorics, linear algebra, and real analysis."

Understanding maths is a crucial part of operations research. However, there are a lot of different routes to operations research, including engineering and physical sciences. Also, because operations research isn't typically taught in high school, university level courses don't assume that their students already understand the maths behind operations research. 


\section{. ASK PROF LARRY SNYDER}

\section{WHAT DO YOU LOVE ABOUT MATHS?}

Maths is about problem solving, about coming up with creative ways to solve problems. I think a lot of people don't like maths in high school because they think it's all about recipes: if you encounter a problem that looks like this, then you should solve it by following these steps. In college, maths is much more creative. If you want to come up with a way to solve maths problems, you have to understand the underlying maths. There's a lot of logic, a lot of trial and error, and a lot of experimentation involved. In fact, doing research scratches the same part of my brain that itches when I solve (or write) puzzles.

\section{WHY DIDN'T YOU WANT TO} CONTINUE TO WORK IN PURE MATHS AFTER YOUR UNDERGRADUATE DEGREE?

Actually, I knew even at high school that I wanted to go into operations research after my undergrad degree. I loved maths at high school, but I didn't really know what sort of careers were possible if I majored in maths in college. Then a graduate of my high school, who works in operations research, gave a talk about operations research to my calculus class. I was hooked immediately.
WHAT WAS IT THAT GRABBED YOUR ATTENTION ABOUT OPERATIONS RESEARCH?

I loved the idea that maths could be applied, and applied to interesting businesses like airlines and health care, so I knew I wanted to go into operations research. But I also really wanted to go to Amherst College, which doesn't have an operations research programme. So, I decided to major in maths at Amherst, then switch to operations research in graduate school, and it worked out great.

WHO HAS INSPIRED YOU THE MOST THROUGHOUT YOUR CAREER? OR IN YOUR CHOICE OF CAREER?

I was fortunate to have a few really good maths teachers in high school, who helped me see the non-recipe side of maths earlier than some students do. I also had terrific maths professors in college, who encouraged me to find my way to operations research even though it wasn't part of the curriculum. They taught me to enjoy the slight feeling of vertigo you get when you start down the path of an idea, but you don't quite know how solid it is or which way it's heading. They also taught me, by example, how much fun it is to teach. And also that maths jokes are awesome!

\section{LARRY'S TOP TIPS FOR STUDENTS}

Take the maths classes that interest you! Every maths class is going to stretch your brain in useful ways, and prepare you to think about whatever new kinds of problems you'll discover later.

When you do maths, let your mind wander. Let yourself think about 2 problems in ways that your teacher didn't suggest.

Explore the ways that maths is linked to your other interests. Maths 3. has a role to play in everything, whether that be music, coding, or even planning out a paper route.

\section{LARRY'S}

FAVOURITE MATHS JOKES!

- A mathematician, an engineer, and a physicist are riding a train through Scotland when they pass a black sheep. The engineer says, "Apparently Scottish sheep are black." The physicist says, "No, all we can say is that some Scottish sheep are black." "No, no," says the mathematician, "all we can say is that some Scottish sheep are black on one side."

- "A mathematician is a device for turning coffee into theorems." Quote from the mathematician Alfréd Rényi 